\title{
Development of a PCR/RLB Test for Meat Source Authentication in Processed Meat and Meat Products
}

\author{
Abbasi Ibrahim $^{1 *}$, Al-Shareef Abdel-Kareem ${ }^{1}$, Matouk Imad ${ }^{1}$, Akkawi Muataz ${ }^{1}$ \\ ${ }^{1}$ Department of Biological Sciences, Al-Quds University, Jerusalem, Palestine.
}

\section{A R T I C LE IN F O}

Article history:

Received 02 August 2014

Accepted 18 December 2014

Available online, ISSN: $2148-127 \mathrm{X}$

\section{Keywords.}

Meat source identification

PCR

RLB

DNA

Food

\begin{abstract}
A B S T R A C T
Concern over food authenticity has increased as a result of an increase in the consumption of processed foods containing meat or animal products. This raises a number of issues where the presence of pork in such foods is considered unacceptable in most Muslim and Jewish communities around the world. It also applied to the prohibition of beef consumption among Hindus. In order to ensure the absence of unwished meat products or mixing of meats from different sources in processed foods, a specific and sensitive test is essential. For this purpose we developed a molecular test based on DNA amplification by polymerase chain reaction (PCR) of the cytochrome $b$ gene followed by reverse line blot analysis (RLB). Using this method many samples may be treated simultaneously and meat origins can easily be detected from processed foods or foods containing mixed meat sources; also, added pork components such as fat may be identified by this methodology. The PCR/RLB method is considered to be a sensitive and specific technique; it can detect one nucleotide change within the PCR-amplified DNA segment.
\end{abstract}

${ }^{*}$ Corresponding Author:

E-mail: iabbasi@science.alquds.edu

\section{Introduction}

The available conventional methods for identification of the meat source for food consumption or identification of animal proteins as a source of food additives are mainly based on protein detection of specific animal species (Hargin 1996, Lumley 1996, Rannoua and Downey 1997). These methods lack sensitivity; they are costly, and also time-consuming. Most of the protein identification tests are not effective after heat treatment of meat due to protein denaturation during processing. Therefore, more reliable and sensitive tests are needed to target stable molecules even after heat treatment or food processing (Rannoua and Downey 1997). DNA-based molecular identification methods are the best choice; these methods are very sensitive and specific; DNA is a remarkably stable molecule allowing analysis of processed and heat-treated food products (Lanzilao and others 2005). Several molecular-based techniques are used for animal identification and for different purposes, for instance: in forensic medicine, in meat inspection of illegal meat trade, in identification of blood meal sources taken by insects, and in meat inspection for human consumption purposes (Murray and others 1995; Ngo and Kramer 2003; Pfeiffer and others 2004; Fajardo and others 2007). Polymerase chain reaction (PCR) is a sensitive test for detecting small amounts of DNA, in which a specific target region of the template DNA is amplified followed by restriction cut of the target DNA that results in specific banding patterns known as restriction fragment length polymorphism (RFLP) (Ngo and Kramer 2003; Bravi and others 2004). This procedure enables a standard comparison among species depending on the amplified DNA fragments of interest. Alternatively, the PCR-amplified DNA fragment can be sequenced in order to determine the specific nucleotide sequence and later species identification (Wolf and others 1999; Terio and others 2010). Species identification by DNA sequencing after PCR is considered costly and laborious; besides it has other major limitations especially when more than one type of DNA source is available or in the case of minute additives of animal products (such as fat).

PCR amplification of mitochondrial genes has been 
used for the differentiation between vertebrate species (Wolf and others 1999). The high copy number of mitochondrial genes, the diversity of their sequences, and the fact that mitochondrial nucleotide sequences of several vertebrates is already determined, are factors that have favored the utilization of mitochondrial genes over nuclear genes for species identification purposes (Kocher and others 1989).

The current study involves the development of a species-specific food additive testing from animal sources (meat, proteins, or even fat) based on PCR amplification of the mitochondrial cytochrome $b$ gene followed by reverse line blot (PCR-RLB) analysis. The PCR-RLB is a highly reproducible technique in which species-specific oligonucleotides are covalently linked through the formation of an amide bond between the carboxyl group present on a nylon membrane and amino-linked oligonucleotides (Saiki and others 1989; Wolf and others 1999). Biotinylated cytochrome b PCR-amplified products are used as probes in a hybridization reaction along with a non-radioactive chemoilluminescent detection system (Saiki and others 1989). This method enables the detection of single base differences among homologous DNA segments or genes. Reverse dot-blot has been widely used in detecting single nucleotide mutations in genetic diseases (Chan and others 1999; Winichagoon and others 1999). This methodology has high potential for identification of animal sources as food additives, especially for pork and beef authenticity.

\section{Materials and Methods}

Animal meat samples: Fresh, well-identified animal meat samples were obtained from local butchers; other commercial canned meat products were obtained from local markets. Meat samples were used directly for DNA extraction as described below.

DNA extraction: DNA was extracted from known animal meat tissues or from tested meat samples using the hexadecyltrimethylammonium bromide (CTAB) extraction method. Homogenized animal tissue was suspended in $0.6 \mathrm{~mL}$ of lysis buffer $(100 \mathrm{mM}$ Tris base, $20 \mathrm{mM}$ EDTA, $1.4 \mathrm{M} \mathrm{NaCl}, 2 \% \mathrm{CTAB}$, and $0.2 \% 2-$ mercaptoethanol) and proteinase $\mathrm{K}(0.2 \mathrm{mg} / \mathrm{mL})$. Following incubation for 3 hours at $60^{\circ} \mathrm{C}$, nucleic acids were extracted twice using phenol followed by chloroform/isoamyl alcohol (24:1), after that DNA was precipitated with $0.2 \mathrm{M} \mathrm{NaCl}$ as a final concentration with the addition of 2.5 volumes of cold absolute ethanol. The obtained pellet was washed with cold $70 \%$ ethanol to remove excess salts, dried and dissolved in $100 \mu \mathrm{L}$ of $\mathrm{TE}$ buffer.

Polymerase chain reaction $(P C R)$ : PCR reaction was carried out on a volume of $50 \mu \mathrm{L}$ containing $200 \mathrm{mM}$ of each dNTP, 25 pmol of the two biotinylated cytochrome $b$ primers (Table 1), 2.5 units of Taq DNA polymerase and the target DNA (5 $\mu \mathrm{L}$ were used from the extracted DNA). The reaction buffer consisted of $10 \mathrm{mM}$ tris- $\mathrm{HCl}$ $\mathrm{pH} 8.3,25 \mathrm{mM} \mathrm{KCl}$, and $3.5 \mathrm{mM} \mathrm{MgCl}_{2}$ ). The used thermal profile involved $5 \mathrm{~min}$ at $95^{\circ} \mathrm{C}$, followed by 35 cycles each of $1 \mathrm{~min}$ at $95^{\circ} \mathrm{C}, 1 \mathrm{~min}$ at $55^{\circ} \mathrm{C}$, followed by $1 \mathrm{~min}$ at $72^{\circ} \mathrm{C}$, and a final elongation step at $72^{\circ} \mathrm{C}$ for 10 $\min$.

Reverse line blot membrane preparation:This was done in two steps: first, membranes were acid-activated then oligonucleotides were bound to membranes. For this purpose Biodyn C (Pall Biomedical, USA) nylon membranes were used, the membranes were activated by $0.1 \mathrm{~N} \mathrm{HCl}$ for $5 \mathrm{~min}$, rinsed with water, and soaked in 10\% 1-ethyl-3-[3-dimethylaminopropyl] carbodiimide (EDC) (Sigma, USA) for $15 \mathrm{~min}$. The membranes were then rinsed with water and air-dried. Species-specific oligonucleotides with 5 '-end amino modification were diluted up to 5 pmoles/ $\mu \mathrm{L}$ and applied on the membrane in a line format with the aid of a manifold apparatus (Immunetics, Cambridge, MA).

Hybridization and colorimetric detection: The membrane-bound oligonucleotides were prepared into strips. The strips were incubated in a pre-hybridization solution (2x SSC, $0.1 \% \mathrm{SDS}$ ) for $30 \mathrm{~min}$ at $45^{\circ} \mathrm{C}$ with gentle shaking. The biotinylated PCR product was denatured by boiling for $5 \mathrm{~min}$ before its addition to the pre-hybridized membrane strip. Hybridization was performed at $45^{\circ} \mathrm{C}$ for 1 hour, then the strips were washed with $0.7 \mathrm{x}$ SSC, $0.1 \% \mathrm{SDS}$ for $20 \mathrm{~min}$. Hybridized biotinylated DNA was detected by incubating the strips in strepavidin-HRP (diluted in 2x SSC, $0.1 \%$ SDS) for 30 min at room temperature, after that the strips were briefly washed 3 times in 2x SSC, $0.1 \%$ SDS. Color was developed after addition of a freshly prepared solution containing $0.1 \mathrm{mg} / \mathrm{mL}$ of 3,3 ',5,5' tetramethylbenzidine (TMB), $0.003 \% \mathrm{H}_{2} \mathrm{O}_{2}$ in $0.1 \mathrm{M}$ sodium citrate $(\mathrm{pH} 5.0)$.

Table 1 DNA sequence of cytochrome b primers and animal-specific oligonucleotides used in reverse line blot analysis.

\begin{tabular}{l|ll}
\hline \multicolumn{1}{c|}{ Sequence type } & \multicolumn{1}{|c}{ Identification } & \multicolumn{1}{c}{ DNA sequence (5' to 3') } \\
\hline PCR primers & $\begin{array}{l}\text { Cytochrome b direct } \\
\text { Cytochrome b reverse }\end{array}$ & $\begin{array}{l}\text { CCATCCAACATCTCTGCTTGATG } \\
\text { TTGTCGACTGAAAATCCCCCTCA }\end{array}$ \\
Animal specific & Beef & CTGCTCACAGTAATAGCCACAG \\
oligonucleotides & Goat & CATTCATAGGCTATGTCCTA \\
& Sheep & CTATTTGCGACAATAGCCAC \\
& Camel & TTGTTCACAGTAATAGCAACA \\
& Pork & TACACACATTTGTCGAGACG \\
& Chicken & CTCCTCACACTCATAGCCACCG \\
\hline
\end{tabular}




\section{Results}

Cytochrome $b$ primers and animal specific oligonucleotides: DNA sequence of cytochrome b gene was compared among the different animal species targeted in this study (pork, beef, goat, sheep, camel, and chicken). This was done by DNA multiple alignment analysis in order to find the most suitable primers that are able to amplify DNA fragments from the different animal species. Also, this analysis enabled the identification of species-specific oligonucleotide probes to be bound to specific membranes in a line format and to hybridize specifically with the PCR-amplified cytochrome b DNA fragments according to the reverse hybridization method. The oligonucleotide probes were selected with at least one nucleotide difference compared to other animal species Table 1 indicates the specific sequences of the primers and oligonucleotides used in this study.

Animal species specific oligonucleotide probes: Table 1 represents a list of some animal oligonucleotide probes that are able to hybridize to cytochrome b PCR products obtained from different animal species. These oligonucleotides can be used to detect specifically amplified DNA for meat inspection or for the presence of animal products in the processed food.

Sensitivity of cytochrome b PCR amplification: The sensitivity limit of the new cytochrome b PCR primers was tested against different DNA concentrations extracted from boiled and unboiled raw pork meat. For this purpose; pork red meat and fat tissue were boiled for 60 min in water and then DNA was extracted and diluted into different concentrations in autoclaved distilled water. Figure 1 shows that the used PCR system is able to amplify cytochrome b DNA fragments from at least $1 \mathrm{pg}$ of boiled and unboiled pork meat and fat. The strength of the amplified bands indicates that this PCR system is able to amplify DNA at lower concentrations.

Reverse line blot (RLB) analysis of the amplified cytochrome $b$ PCR products: Cytochrome b PCRamplified products using genomic DNA from the studied animals were analyzed by reverse line blot hybridization. About $0.1 \mathrm{ng}$ genomic DNA obtained from known animal sources was used in a separate PCR amplification reaction (Figure 2). Cytochrome b PCR system amplified DNA from the 6 animal species (chicken, camel, goat, sheep, beef, and pork). The individually produced PCR DNA was tested in reverse hybridization against homologous species-specific oligonucleotides by RLB configuration. All the bound probes showed a discrete hybridization with no cross-hybridization with any other animal species (Figure 2b).

Meat identification by $P C R$ / RLB: The effectiveness of the meat identification test (combined PCR and RLB analysis) was studied in two different strategies: identification of mixed meat products, and identification of known brands of local commercial meat products. In the first strategy, about $5 \mathrm{~g}$ of pork was mixed with $5 \mathrm{~g}$ of beef and $5 \mathrm{~g}$ of goat, the mixture was ground, similarly ground homogenized goat and pork was made. From each preparation about $0.5 \mathrm{~g}$ was taken for DNA preparation and later analysis by PCR/RLB. Figure 3 a shows that after mixing the different meat sources with pork DNA, it was still possible to amplify DNA by the cytochrome $b$ PCR system, but it was not possible to differentiate between the amplified DNA from the different sources on agarose gel electrophoresis. On the other hand analyzing the PCR products by reverse hybridization can easily identify the type of the mixed meat sources (Figure $3 b$ ). The three mixed animal meats amplified cytochrome $b$ DNA segments were hybridized each to its homologous specific probe; this indicates the effectiveness of using this test in identifying mixed meat sources.
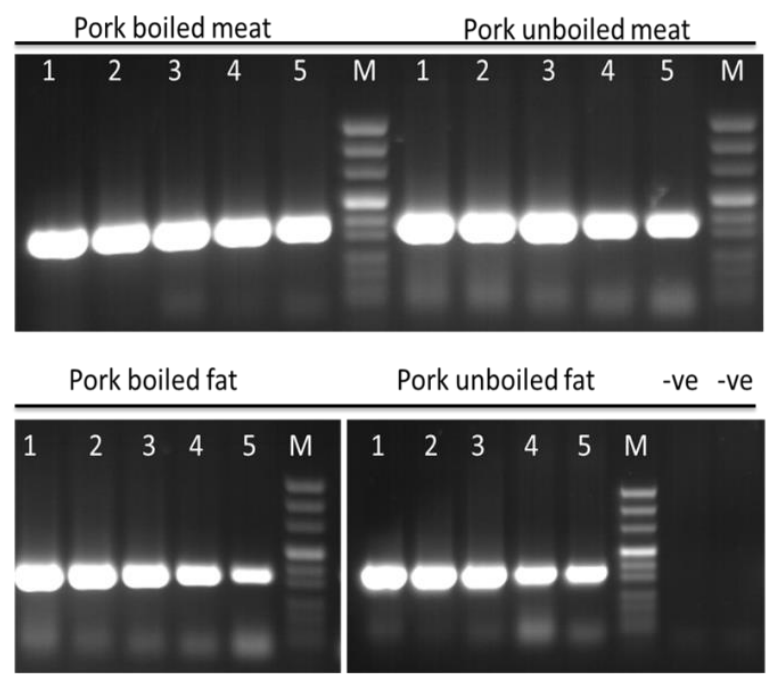

Figure 1 Sensitivity of PCR amplification of cytochrome b DNA fragment from different DNA concentrations extracted from raw and boiled pork meat and fat. (1- 50 ng of DNA, 2- $1 \mathrm{ng}, 3-0.1 \mathrm{ng}, 4-0.01 \mathrm{ng}, 5-1 \mathrm{pg}$ ( MDNA size marker).

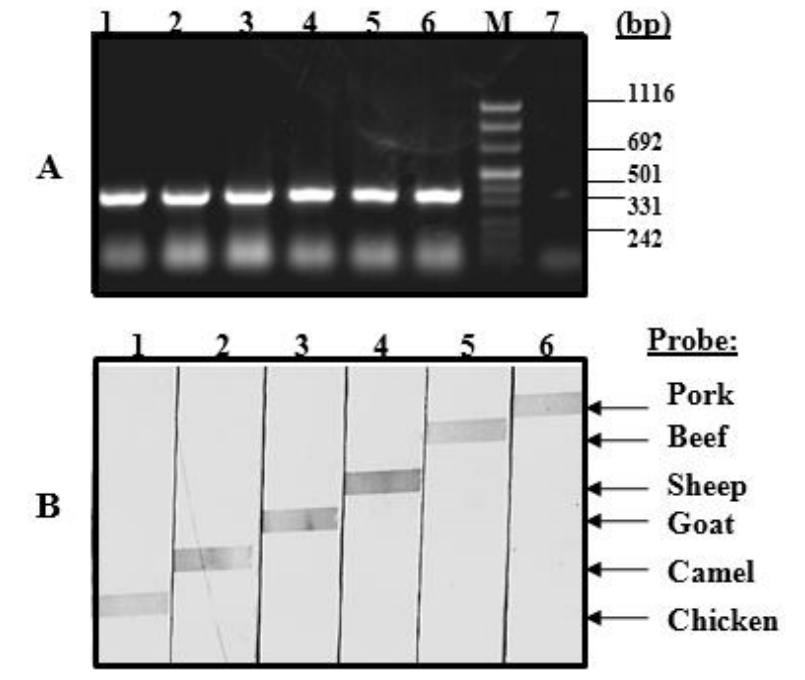

Figure 2 PCR amplification of cytochrome $b$ DNA fragment from different animal meats (A) and its corresponding reverse line blot analysis (B). Cytochrome b DNA fragment was amplified from 1- Chicken, 2Camel, 3- Goat, 4- Sheep, 5- Beef, 6- Pork. The arrows in (B) indicate the site of the different animal oligonucleotides on the RLB membrane. 


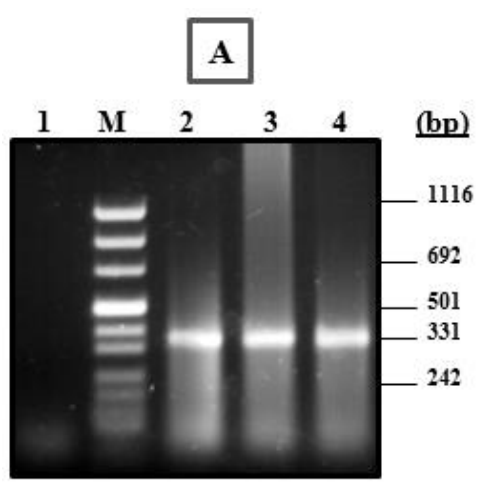

B

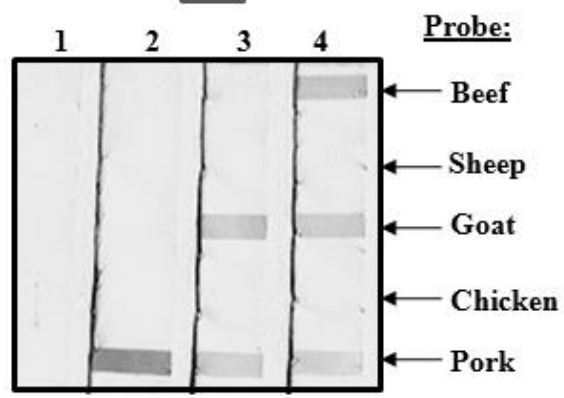

Figure 3 PCR amplification of cytochrome b DNA fragments targeting DNA prepared from mixed sources of animal meats (A) and its corresponding reverse line blot analysis (B). Cytochrome b DNA was amplified from the following preparations: 1- No DNA control, 2- pure pork, 3- mixed pork and goat meat, 4- mixed pork, goat, and beef. Arrows in B indicate the location of each animalspecific oligonucleotide on the RLB membrane.
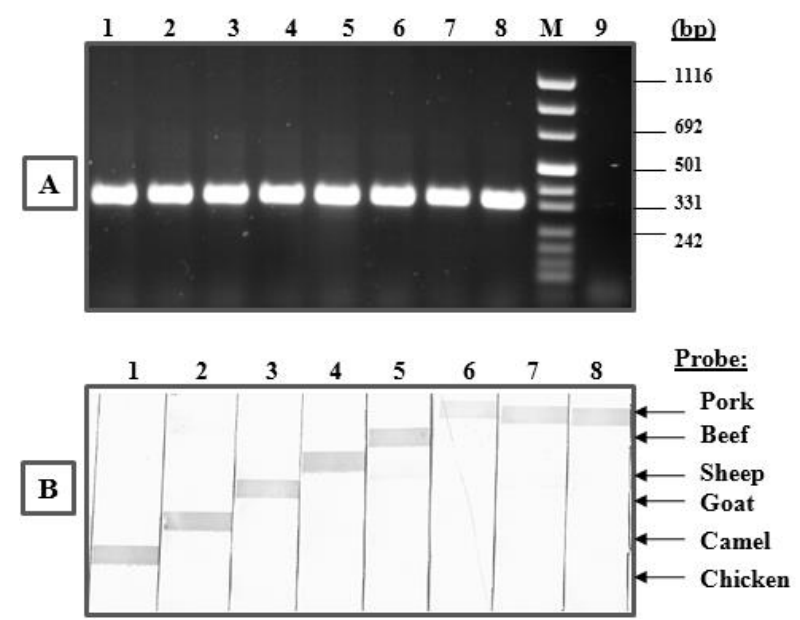

Figure 4 PCR amplification of cytochrome b DNA fragment from different commercially available meat products (A) and its corresponding reverse line blot analysis (B). Cytochrome b DNA was amplified from 1commercial cold chicken meat, 2- fresh boiled camel, 3goat, 4- sheep meat, 5- canned beef, 6,7 - different brands of canned pork, 8- fresh pork, 9- No DNA control. The arrows in (B) indicate the site of the specific animal oligonucleotides on the RLB membrane.
The second strategy was based on direct identification of some known commercial meats. For this purpose, canned meat sampler of beef and pork origins were tested as well as samples of cold smoked chicken, fresh goat, sheep, and camel origins. DNA was extracted from $0.5 \mathrm{~g}$ of all the tested meat types and it was subjected to cytochrome b PCR amplification and then analyzed by RLB. It can be clearly seen (Figure 4) that the cytochrome b DNA fragments were amplified from the entire extracted DNA, and the amplified products hybridized with its corresponding oligonucleotide probes in RLB analysis. These results indicate the purity of the tested meat sources and the effectiveness and robustness of the PCR / RLB analysis method for meat source identification.

\section{Discussion}

The main objective of this study was focused on the development of a sensitive and reliable test for meat source identification in raw and cooked meat products, besides the importance of such tests in meat adulteration with cheaper sources. The test is based on three main steps that include DNA extraction form meat products, amplification of DNA segments from cytochrome $b$ gene by PCR, followed by reverse hybridization analysis of the PCR product to species-specific oligonucleotide probes bound to specific nylon membranes. The reverse hybridization method was called RLB simply because the used probes were bound to the nylon membrane in a line format, with the same principle of reverse dot blot (RDB), in which the probes were bound to the membrane in a dot format (Saiki and others 1989). The combination of PCR and reverse blot analysis has proven to be effective in the identification of many single nucleotide mutations or polymorphisms in genetic diseases (Sutcharitchan and others 1995). Later on this approach (PCR/RDB) was used in the identification of many pathogenic diseases, especially when species-specific identification was needed (Stothard 2001; Lopez-Jimena and others 2010).

The adapted PCR amplification system was based on cytochrome $b$ gene for its being one of the most abundant and shared genes among different animal species especially those used in the meat industry. This gene was also targeted in other previous studies focused on animal species identification for different purposes (Lanzilao and others 2005; Fajardo and others 2007). These studies were mainly based on DNA amplification by PCR followed by restriction enzyme (Girish and others 2005) analysis, sequence analysis (Terio and others 2010), and the adaptation of new analysis methods such as real-time PCR followed by high-resolution melt (HRM) analysis. The major disadvantages of restriction enzyme and HRM analysis is their suitability to discriminate only among a few animal species, so for restriction cut analysis using restriction enzymes, it is difficult to find polymorphic differences that cover a wide range of animal species and, similarly, the HRM. The existing polymorphism in small DNA segments is not enough to be expressed by melting curve analysis over a narrow range of temperature. Animal species identification by DNA sequencing is 
considered an effective analysis tool only if enough PCR products can be obtained and if there is no mixing between more than one animal species which is not applicable in most of the cases in meat processed food, since direct DNA sequencing can only be performed with one type of DNA product, and if there is more than one source of DNA; the sequence analysis will be of no significance in species identification. The only solution for such sequencing problem is to clone the PCR product which is costly and time-consuming, and the amplified DNA fragments with low concentration will be missed. In contrast to these methods, the combined PCR and RLB method enables multispecies identification of the animal meat source. This is because the method depends on two independent procedures, the PCR amplification that will amplify the cytochrome $b$ gene segment from any source, followed by the independent and specific hybridization of the different amplicons each to its corresponding membrane bound specific oligonucleotide probe. Our test can be adapted for two main purposes, first; for pork meat or fat authentication from other types of meats or even in other products for religious purposes in some communities. Second; for meat type verification for trading purposes and for the benefit of the consumer, especially after meat processing (canning, cold meat cuts) where there is a chance of partial substitution of meat from a high-value species by meat of lower value.

The selected primers that were used in the current cytochrome b PCR amplification were designed based on shared sequences of this gene from different animal species and that in order to amplify cytochrom $b$ gene fragment from a wider range of animals including avian. Also, theses primers were spanning a region that showed less similarity in the gene sequence and this allows the design of animal-specific oligonucleotide probes to be used in a reverse hybridization reaction. One of the factors that limit obtaining a successful RLB signal is the concentration of the PCR products, so it is very important to have a sensitive PCR system in order to enrich the hybridization reaction. Our system has a sensitivity limit that exceeds $10 \mathrm{pg}$ of DNA, and this corresponds to the amount of DNA in less than a few milligrams of any meat source, so any little contamination of a specific meat type may be identified.

\section{Conclusion}

Meat source identification was achieved by PCR amplification of a cytochrome b DNA segment that have few nucleotide polymorphism which enables further meat species identification by reverse line blot analysis. The combined PCR/RLB method can discriminate between meat species sources even if they are mixed.

\section{Acknowledgment}

This study was supported by the Arab Science and Technology Foundation, grant number BT072239.

\section{References}

Bravi CM, Lirón JP, Mirol PM, Ripoli MV, Peral-García P, Giovambattista G. 2004. A simple method for domestic animal identification in Argentina using PCR-RFLP analysis of cytochrome b gene. Leg Med (Tokyo) 6: 246-51.
Chan V, Yam I, Chen FE, Chan TK. 1999. A reverse dot-blot method for rapid detection of non-deletion a thalassaemia British Journal of Haematology, 104: 513-515.

Fajardo V, González I, López-Calleja I, Martin I, Rojas M, Pavón MA, Hernández PE, García T, Martín R. 2007. Analysis of mitochondrial DNA for authentication of meats from chamois (Rupicapra rupicapra), pyrenean ibex (Capra pyrenaica), and mouflon (Ovis ammon) by polymerase chain reaction-restriction fragment length polymorphism. J AOAC Int. 90: 179-86.

Girish PS, Anjaneyulu AS, Viswas KN, Shivakumar BM, Anand M, Patel M, Sharma B. 2005. Meat species identification by polymerase chain reaction-restriction fragment length polymorphism (PCR-RFLP) of mitochondrial 12S rRNA gene. Meat Sci. 70: 107-12.

Hargin KD. 1996. Authenticity issues in meat and meat products. Meat Sci. 43: 277-289.

Kocher TD, Thomas WK, Meyer A, Edwards SV, Pääbo S, Villablanca FX, Wilson AC. 1989 Dynamics of mitochondrial DNA evolution in animals: amplification and sequencing with conserved primers. Proc Natl Acad Sci USA. 86: 6196-200.

Lanzilao I, Burgalassi F, Fancelli S, Settimelli M, Fani R. 2005. Polymerase chain reaction-restriction fragment length polymorphism analysis of mitochondrial cytb gene from species of dairy interest. J AOAC Int. 88: 128-35.

Lopez-Jimena B, Cherif N, Garcia-Rosado E, Infante C, Cano I, Castro D, Hammami S, Borrego JJ, Alonso MC. 2010. A combined RT-PCR and dot-blot hybridization method reveals the coexistence of SJNNV and RGNNV betanodavirus genotypes in wild meagre (Argyrosomus regius). J Appl Microbiol. 109: 1361-1369.

Lumley ID. 1996. Authenticity of meat and meat products. In: Food Authentication, ed. Ashurst PR, Dennis MJ, Blackie Academic and Professional, London. 1996 p. 108.

Murray BW, McClymont RA, Strobeck C. 1995. Forensic identification of ungulate species using restriction digests of PCR-amplified mitochondrial DNA. J Forensic Sci. 40: 943-51.

Ngo KA, Kramer LD. 2003. Identification of mosquito bloodmeals using polymerase chain reaction (PCR) with order-specific primers. J. Med. Entomol. 40: 215-222

Pfeiffer I, Burger J, Brenig B. 2004. Diagnostic polymorphisms in the mitochondrial cytochrome $\mathrm{b}$ gene allow discrimination between cattle, sheep, goat, roe buck and deer by PCR-RFLP. BMC Genetics, 5: 30.

Rannoua H. and Downey G. 1997. Discrimination of raw pork, chicken and turkey meat by spectroscopy in the visible, nearand mid-infrared ranges. Analytical Communications 34: 401404.

Saiki RK, Walsh PS, Levenson CH, Erlich HA. 1989. Genetic analysis of amplified DNA with immobilized sequence-specific oligonucleotide probes. Proc. Natl. Acad. Sci. 86: 6230-6234.

Stothard DR. 2001. Use of a reverse dot blot procedure to identify the presence of multiple serovars in Chlamydia trachomatis urogenital infection. J Clin Microbiol. 39: 2655-2659.

Sutcharitchan P, Saiki R, Huisman TH, Kutlar A, McKie V, Erlich H, Embury SH.1995. Reverse dot-blot detection of the AfricanAmerican beta-thalassemia mutations. Blood. 86: 1580-1585.

Terio V, Di Pinto P, Decaro N, Parisi A, Desario C, Martella V, Buonavoglia C, Tantillo MG. 2010. Identification of tuna species in commercial cans by minor groove binder probe realtime polymerase chain reaction analysis of mitochondrial DNA sequences. Mol Cell Probes. 24(6):352-6.

Winichagoon P, Saechan V, Sripanich R, Nopparatana C, Kanokpongsakdi S, Maggio A, Fucharoen S. 1999. Prenatal diagnosis of $\hat{a}$-thalassaemia by reverse dot-blot hybridization Prenat. Diagn. 19: 428-435.

Wolf C, Rentsch J, Hübner P. 1999. PCR-RFLP analysis of mitochondrial DNA: A reliable method for species identification J. Agric. Food Chem. 47: 1350-1355. 